\title{
Henry Kempe
}

Henry Kempe's contributions to paediatrics were so outstanding that it is appropriate for the Archives to publish a few paragraphs about him, not so much as an obituary but rather as a reminder to paediatricians of how much we owe him.

As a virologist and immunologist he was the first to recognise that in the United States after the Second World War the risks from vaccination against smallpox had become greater than those from the disease itself, and he saw it as his duty to persuade colleagues and authorities to stop routine vaccination: later, he played a major role in the successful world wide drive to eradicate smallpox.

Paediatricians working in the west will remember him mainly for his recognition of the "battered child syndrome'. Younger paediatricians may not appreciate the measure of this contribution. My generation had been trained to assume that all parents loved their children and did their best for them, and to believe every word spoken by the mother about her child. When confronted by an infant or toddler with bruises and fractures for which there was no easy explanation, the paediatrician would consider all manner of rare haematological and skeletal disorders subjecting the patient to many tests. It required Henry Kempe's fertile mind and courage to break away from orthodox teaching and see the reality. Even after his early papers on child abuse it was a long time before the profession was convinced. In those days the suggestion that a child might have been maltreated by his parents led to heated arguments between members of the professional team caring for the child. Even today, in discussions of a difficult diagnostic problem it is useful to consider non-accidental injury as a possibility whenever strong disagreements and tensions arise between members of a team who usually work together amicably.

One measure of the influence of Henry Kempe's work is to note developments which have stemmed from his original observations. We now know that parents can and do inflict harm on their children in many and sometimes bizarre ways. Of these, emotional deprivation is probably the most common and although we are learning to recognise the resulting clinical picture in infancy and early childhood, we are still slow to recognise it in the case of older children. The diagnosis of sexual abuse still tends to be too long delayed. Another form of child abuse only recently recognised is Munchhausen syndrome by proxy and its many variations.

There is much we can learn from Henry Kempe's life. The particular lessons I would like to remember are: that it is possible for the same man to make important contributions to the science of paediatric medicine as well as to its art; and that it is possible for a paediatrician, even one who by nature is shy, gentle, and sensitive, to play his part in bringing about changes in the outlook of his profession, of society and even the law, once he sees the need for such change.

When we attempt to measure the greatness of a man's contribution, one useful question we may ask is 'did his observations open the eyes of others and lead them to extend his original vision?' By this and other criteria Henry Kempe was a great man.

OtTo H WolfF 